\title{
Nepalese Society in Response to TEVT Programs
}

\author{
Luman Lama
}

\begin{abstract}
Technical education and vocational training programs in Nepalese society have been a aloud offbeat that is combating to slice through the prevalent socio-economic and contemporary social setup so that it could contribute at the very best. Despite more than a half a century's effort to establish it as a strong element that supports the country's economy and peoples' living standard, it has still been straining somewhere near the beginning point. This study investigates some impeding socio-cultural factors that fade the overall development of TEVT programs. The result should help the policy makers to be more assured about the major issues that hurdle the TEVT setup in Nepalese society. Analyzing several research works and national and international reports on concerned topics it is found that the TEVT values have not been placed as one of the top national priorities due to the existing social setup and people's perspective towards TEVT programs. Therefore the heterogeneous aspects are required to be synchronized even more tactically along with TEVT's integration in the labor market in order to choreograph, qualitatively improved TEVT programs so that TEVT could be significantly potential element among those on which the country's socio-economic development could depend on more reliably.
\end{abstract}

Keywords: Vocational, Education, Training, TEVT.

\section{Introduction}

Suction! That held the general peoples' living standard within a constrain of poverty is similar as ever in Nepal, standing at 157 position out of 186 countries in Human Development Index ranking 2013. One of the responsible factors for this is definitely a poor literacy rate which reads $65.9 \%$ according to 2011 national census. 
Nepal has a GDP of $4.63 \%$ in 2011 and with $1.35 \%$ of population growth rate, $25.16 \%$ of total population still lives in below poverty line according to 2011 census. Some International Organizations have recommended the basic education and also vocational education and training to fight against poverty. In fact UNESCO Institute of Statistics (UIS) has expressed the simple correlation between TVET and economy as 'the greater a country's Gross Domestic Product per capita, the greater its secondary percentage of Technical/Vocational enrollment' (UIS, 2006). 67 years of effort to consolidate Vocational Education and Training (VET) in Nepal by now, is yet to witness a better change in VET concerned domain. Number of factors like socio-cultural and economic factors, people's perspective towards VET, lack of integration of VET and market, failure of choreography of VET policies in a society etc could be analyzed for meager effect of policies drafted for VET. Another fact is introduction of vocational education in formal education has not been fruitful, moreover vocational education and training in higher level has been even difficult. School Sector Reform Plan (SSRP) has encouraged to introduce vocational education in formal education to achieve the goals for Education For All (EFA) but numbers of elements are still hindering the approach. The technical education and vocational training component of SSRP aims at providing work oriented soft skills to secondary school students. However, expansion and consolidation of Technical Education and Vocational Training (TEVT) programs require a significant level of resource mobilization for technical capacity building; infrastructural development; and teacher preparation including equipment support (DOE, 2012a). Similarly vocational education in higher levels has been emphasized by SSRP but the executions of policies have not been up to the expectation. 'Higher education of Nepal has been facing problems related to access quality, relevancy, economic sustainability etc' (DOE, 2012b). Social setup in the context of Nepal is saturated with caste and class, traditional behavior patterns hence the prosperity in TVET program is stumbling quite a lot. Wolfgang (2010a) 'Though several South Asian countries have initiated well planned TVET programs, but persistently strong socio-cultural value patterns seem to discourage student from entering technical 
and vocational training, even in secondary schools as manual labor and training are widely considered of much lesser prestige than learning at the hands of book'.

Caste and class wise, many indigenous groups and back ward classes in Nepal are battling hard just to notify their existence and not to compete with the rest. Literacy rate and school enrollment rate among these groups are comparatively low plunging many of them below the poverty line. In this context the geographical structure of the country and the population distribution is responsible to a great extend for such prevalence. Moreover ten years of Maoist insurgence in the country has left thousand of Nepalese homeless hitting hard financially, politically and socially jeopardizing their dreams, careers and scopes. Displaced peoples' basic challenge was to reestablish themselves and any kind of initiations to be enrolled in formal education or any other training for them was of second priority. Truly the mental status of those people to deal formal education after such a gap was even difficult. So to set vocational education and training in such social structure is indeed a challenge therefore the policies regarding VET requires further research so that they could be more utilitarian, helping general public to live quality of life along with the development of economy in the country.

\section{Historical Background of Vocational Education and Training Initiatives in Nepal.}

It is seen that the people were attributed to the occupations as per their caste due to the existing caste system in Nepal prior to freedom from Rana in 1950. However some initiations were taken up before the democracy to establish training centers. Usha (1999) explains that 'Several schools and training centers were opened, all targeting to expand the services to the public. One of such efforts was the opening of vocational skill training with the first training cum production in spiny and hosiery in central jail, targeting to inmates. Others were namely; leather processing and shoe making production center in Balaju, Kathmandu in 1929; the Cottage Industry Promotion Office in 1939; and similar centers in Dhankuta and Palpa in 1942 and 1944'. In the influence of Mahatma 
Gandhi's philosophy about basic education system in 1947, the vocational education program, with the objective to enable people to be self reliance and economically independent, was launched by the then Rana Regime but this program could not sustain after the democracy. Instead it was improvised a bit. The greater emphasis was given on the practice of vocational skill, expecting schools to offer basic craft together with other general subjects (MOE, 2009a). Though the basic education system was terminated, it was distinct milestone in VET history in Nepal. Multi Purpose Education system was then kicked off in 1958 after the basic education. The objective of multipurpose education system was to produce technical manpower within the country but the program was again not flawless as guardians did not show a positive response. Equity consideration was not distinct in multipurpose education system (MOE, 2009b) hence the number of multipurpose schools gradually began to decrease. Further, these schools later encountered several problems such as irrelevant curricula, low employment outcomes and poor social image of vocational education (Belbase, 1981). Consequently this program was brought to an end.

In 1971 National Education System Plan (NESP) introduced a compulsory vocational education in all the secondary schools with an objective to produce medium level manpower. The program remained in action for about 5 years and sadly followed the same old trend as in the past. This was a failure too. Due to the several problems highlighted by the mid-term evaluation of NESP the program was discontinued. However the journey to Technical School System did not end here. Access and equity were the key dimensions of social inclusion in the program therefore a new effort to embody an access and equity in the program, as envisioned in the past, was included in the Work Plan 1979 prepared by the National Education Committee, and eventually technical school program were introduced in some remote areas but this did not work either. After a failure of series of programs to consolidate VET in the country, Council for Technical Education and Vocational Training (CTEVT) was finally established in 1989 under CTEVT Act 1989 to formulate policies and program, to control quality and to implement programs. CTEVT since then is working to expand the services to 
wider population and to promote quality of the program. Besides, Department of Labor and Employment Promotion, Department of Cottage and Small Industries are also contributing to promote CTEVT. GoN together with several other international partners have employed several norms such as quota, scholarships etc. (ADV, 2006).

\section{Socio-cultural Perspective and VET}

Nepal is unique country due to its culture and tradition. Many norms and values, whether advantageous or not, are nurtured by the socio-cultural importance. Caste and class system is an important feature of Nepalese culture which has become their identity. After the unification in 18th century, open society and melting pot concept started to end and closed society with vertical hierarchy of caste system started to enforce (Bista, 1982). Peoples' occupation was a kind of an attribution to their caste. Moreover Nepalese peoples' traditions have also confined people into a situation that provides a social mandate to be particular in themselves. This root causes to some extend is responsible for not being able to sync Nepalese societies effectively with vocational education and training programs even in the present context. Therefore it is worth to analyze some of them in order to find out the key issues related to VET in Nepalese society.

\section{Caste and Class}

Nepal is a country dominated by Hindu religion. It is believed that the Nepalese culture is a hybrid of Indo Aryan and TibetoBurman culture. However Hinduism is strongly embedded in Nepalese society and the caste principles were developed on the basis of Hindu texts, furthermore from the beginning of Rana period the caste stratification was reinforced strongly. Division of labor was based on the caste system which was basically the division of occupation (Bista, 1961). Another feature of division of labor was its inheritance. Nepali social structure was based on caste hierarchy system, which was closed system and determined the division of labor by birth (Bista, 1989). This means the community traditions governs specific jobs and skills. For instance the son of potter to be 
potter as in the case of Kumals (basically known for an occupational caste who make earthen ware pots), son of gold smith to be gold smith as in the case of Sunars, son of singer to be singer as in the case of Gaine (Known for an occupational caste who sing traditional songs with an instrument, Sarangi) etc. Wolfgang (2010b) expresses as 'In addition to the generational transmission of traditional professional skills, countries like India and Nepal, where Hinduism is still governing most of the socio-cultural relations in rural areas, are also confronted with caste defined behavior. It implies that many trades/professions especially those involving manual work, belong to well defined sub caste and it would be almost impossible for a young member of such a professional sub caste to enter a different profession within sight of his community. He would run the danger of losing his social identity'.

We have to acknowledge here that any kind of vocational education and training (VET) program could be effected especially in rural areas by the caste and class system resulting in low enrollment in such program. According to the UIS data, the number and percentage of secondary school age population enrolled in vocational courses was 20546 which is $0.5 \%$ in Nepal (Prospects, 2005). CTEVT (2011a) expresses the difficulties in enrollment as 'Instead of controlling the quality government in its five years plan has given emphasis on expanding the programs targeting to provide short term TEVT training to 23555 persons, long term training for 7500 persons and expanding the annex programs in all seventy five districts of Nepal during tenth five year plan, which seems ambitious if we assess the progress of first two years of tenth five years plan'. However introductory contents on vocational skills are integrated in grade 6 to 8 curricula and vocational curricula focusing on soft skills is developed for secondary education as a pilot project. Whatsoever the policies are, students get to learn vocational skills up to grade 8 under SSRP. Though present formal education in secondary level has vocational education as an optional subject, it has remained as a fallacy therefore it has not become a popular subject to follow. Moreover due to its high cost and lack of concerned trained teachers most of the schools do not prefer to adapt it.

Similarly a practice of caste hierarchy has confined the socio- 
economic development. Some of the ethnic groups (Dalits) have lowest status in Hindu society. They are deprived from auspicious social and cultural function in the society just because of their low caste. Consequently their participation in many social activities is very less otherwise nil especially in rural part of the country. Wolfgang (2010c) further elaborates the belief in caste system as 'Caste defined behavior also involves acceptance of the nation of perceived spiritual impurity and even pollution, when a member of a lower or very low caste accidentally touches other objects or working areas where higher caste members could consider of being "polluted", or have become "unclean", through indirect contact with a low caste. This behavior still holds in large area in rural India and Nepal'. Wolfgang acknowledges that the existence of rigid local professional framework could bar people belonging to low caste from accessing professional training and education. Indeed, Wolfgang's claim can be proven by the educational data. 'The share of Dalit enrollment is $20.3 \%(21.7 \%$ in the last school year) at primary level, $14.6 \%$ (14.6\% in the last school year) at lower secondary, $10.6 \%(10.5 \%$ in the last school year) at secondary and $7.6 \%(6.8 \%$ in the last school year) at higher secondary levels' (DOE, 2012). According to the Flash I Report of 2012 the percentage of enrolment of Dalits in secondary and higher secondary level has increased by little when compared to Flash I Reports of 2011. Whereas there was no change in lowers secondary level but there was a decrease of $1.4 \%$ in primary level when compared to 2011 's report. To wrap up as a whole the enrolment of Dalits are still low. Moreover the Flash I Report explains that the total number of students have decreased by $4.5 \%$ in primary level, however the number has increased by $0.6 \%$ in lower secondary level. Another challenge for VET is indigenous groups who do not have the favorable social infrastructure to make easy access in several social functions.

It is also important to look into the indigenous group in regards of enrolment to understand socio-cultural perspectives for training and education in Nepalese society. According to Flash I report under MOE in 2012 the enrolment of indigenous group in primary level was $35.4 \%$, lower secondary level was $39.8 \%$, secondary level was $38.8 \%$ and higher secondary level was $35.4 \%$ whereas 
the percentage in 2011 reads as $37.6 \%$ in primary, $40.8 \%$ in lower secondary, $40.4 \%$ in secondary and $31.5 \%$ in higher secondary level. Moreover the enrolment number of extremely disadvantaged indigenous group in 2012 shows 90405 in primary level, 31513 in lower secondary level, 14377 in secondary level and 2737 in higher secondary level. Whereas these numbers in 2011 reads 81814 in primary, 23872 in lower secondary, 8319 in secondary and 2737 in higher secondary. According to 2001 census the list of indigenous nationalities recognizes 59 indigenous group comprising $38.5 \%$ of the 23 million people in Nepal.

What we must consider here is indigenous groups lie within the low caste and National Foundation for Development of Indigenous Nationalities (NFDIN) defines indigenous nationalities as 'those ethnic groups or community, who have their own mother tongue and traditional customs, different cultural identity, distinct social structure and written or oral history'. Civil Code in 1854 had legally categorized indigenous people as the matwali or liquor-drinking caste, second in the four fold caste hierarchy, and further sub divided into a group that is convertible to slave and a group unconvertible to slave. The literacy rate has been comparatively low despite National and International efforts. As far as Dalits are concerned the situation is even worse there is only $13 \%$ share of population (CBS, 2011) however Dalit civil society have been claiming it to be more than $20 \%$ of the total population. Therefore more effective policies are required to improve Indigenous and Dalits participation in education programs with justification in regard of human value.

\section{Traditional Behavior Patterns}

Traditional behavior pattern in Nepalese society is a vital and vivid reason that makes difficult for vocational education and training programs to develop. The social structures and functions that have been shaping Nepalese society for ages still haven't framed the utilitarian approach that allow the socio-economic development to expand in accordance to modern values. Certain traditions like kinship, family structure, marriage system as well as gender value from religious insight play an important role in forming specific behavior patterns which consequently disturbs vocational education 
and training program to reach most of the needy people. In fact a century old complex traditional values still governs many peoples' life especially in rural areas of Nepal.

Most of the families in Nepalese society have a characteristic of patrilineal pattern. Moreover Nepalese culture supports joint family system. Family structure in Nepalese society has a direct or indirect impact in schooling or attaining any kind of extra training. Typical family tradition demands females to carry out household works whereas it demands males to deal with the works outside the house. Many school age girls are thus occupied more at household works rather than going to school or joining any kind of vocational trainings. Furthermore on one hand patrilocal system discourages people from sending their daughters to school or educating them otherwise, on the other hand due to the less value of education especially for the girls, the girls themselves don't turn desperate to pursue education in such family, in addition to that domestic works make their education difficult if they even attempt to study. Hence girls' education is not prioritized in typical Nepalese family system. Wolfgang (2010d) explains 'Tradition covers wide and complex variety of social behavior patterns where strict rules of kinship play a major role. Through the kinship structures professional activities and place of a woman in the community can be identified.

Heritage and property follow patrilineal pattern in most of the Nepalese societies. Though civil code provides right to daughters to claim ancestral property, sons' position is much stronger and promising as compared to daughters in this context. However daughters reclaim their liability for property and heritage after getting married. This means as a wife she gets right on husband's property even after the death of her husband. That is how the kinship structure in Nepalese society encourages girls to get married than to study especially in rural areas and to some extend in urban areas too. Therefore early marriage is quite prevalent in Nepalese society especially in case of daughters. Early marriage system in Nepalese, society is not a new scenario and after a desperate effort from national and international level, child marriage and early marriage cases have reduced a lot. However the National census figure in 2011 is still not appreciable. Let's observe the age at first marriage 
up to 19 years in Nepal.

Table 1. Age at First Marriage in Urban Area

\begin{tabular}{|l|l|l|l|}
\hline \multirow{2}{*}{\multicolumn{1}{c|}{ Sex }} & \multicolumn{3}{c|}{ Age } \\
\cline { 2 - 4 } & Below 10 years & $10-14$ years & $15-19$ years \\
\hline Male & 3334 & 28635 & 249860 \\
\hline Female & 17456 & 147501 & 627169 \\
\hline Total & 20790 & 176136 & 877029 \\
\hline
\end{tabular}

Source: CBS 2011.

Table 2. Age at First Marriage in Rural Area

\begin{tabular}{|l|l|l|l|}
\hline \multirow{2}{*}{ Sex } & \multicolumn{3}{c|}{ Age } \\
\cline { 2 - 4 } \multicolumn{1}{c|}{} & \multicolumn{1}{c|}{ Below 10 years } & $10-14$ years & $15-19$ years \\
\hline Male & 19531 & 232597 & 1926924 \\
\hline Female & 97694 & 954384 & 3713328 \\
\hline Total & 117225 & 1186981 & 5640252 \\
\hline
\end{tabular}

Source : CBS 2011.

It is clear from the above tables that child and early marriage is widely practiced still today. Observing the age at first marriage in three age groups viz. below 10 years; 10 - 14 years and 15 - 19 years it is seen that the number of girls is far greater than that of boys. Which is $68 \%$ more each in below 10 years and $10-14$ years of age group whereas it is $44 \%$ more in 15 - 19 years of age group in urban areas. As far as rural areas are concerned the cases are quite similar, it reads $68 \%, 60 \%$ and $32 \%$ more girls get married as compared to boys in below 10 years, 10 - 14 years and 15 - 19 years of age group respectively. According to the civil code marriageable age is 18 years in Nepal. Girls get married more in early ages.

\section{Employment in Abroad, Migratory Culture and TEVT Status in Nepal}

Youths migration for employment is one of the serious challenges that bars vocational education and training programs to have adjusted in Nepalese society. Success of TEVT programs depend on peoples' participation in it. The flourishing migratory culture has turned out to be a better option for people to live qualitative life. People with very little or no qualification, training and skills are making their way to abroad at reasonable expenses for 
the purpose of employment and this trend has been promising than the other means. Therefore the demand for the vocational education and training from the public side is not intensified, eventually there is no desperate efforts to promote TEVT programs from government side too. This fact can be illustrated from the government's plans. Allocation of public resources to TEVT by years appears as follow.

Table 3. Allocation of Public Resources to TEVT by Years (in millions)

\begin{tabular}{|l|c|c|c|c|c|}
\hline Title & $2007 / 08$ & $2008 / 09$ & $2009 / 10$ & $2010 / 11$ & $2011 / 12$ \\
\hline GDP & 815700 & 988300 & 1193700 & 1369400 & 1558000 \\
\hline National budget & 168996 & 209416 & 256480 & 306496 & 384900 \\
\hline Education budget & 28390 & 39086 & 46617 & 57828 & 63919 \\
\hline TEVT budget & 3841 & 5920 & 6477 & 7345 & 9618 \\
\hline $\begin{array}{l}\text { \% of TEVT budget in } \\
\text { GDP }\end{array}$ & 0.471 & 0.599 & 0.543 & 0.536 & 0.617 \\
\hline $\begin{array}{l}\text { \% of TEVT budget in } \\
\text { national budget }\end{array}$ & 2.27 & 2.83 & 2.53 & 2.40 & 2.50 \\
\hline $\begin{array}{l}\% \text { of TEVT budget in } \\
\text { education budget }\end{array}$ & 13.53 & 15.15 & 13.89 & 12.70 & 15.05 \\
\hline
\end{tabular}

Sources: Economic surveys and Red Books by Ministry of Finance (MoF 2001 / 05 to 2010 / 11) and White Books (Books of Annual Programs) by National Planning Commission (NPC 2004 / 05 to 2010/11)

There is a constant increase in GDP in National and educational budget from year 2007/08 to 2011/12. Though the trend in TEVT budget within the same period of time has increased the percentage of TEVT budget in GDP and National budget has somewhat fluctuated during 2009/10 and 2010/2011 it has plunged into less amount as compared to 2008/09. However in 2011/12 some improvement in the percentage of TEVT budget has been observed. Similarly the percentage of TEVT budget in education budget has shown same trend as above. The percentage has dropped during 2009/10 and 2010/11 and it has again puffed up a little in 2011/12. World Bank (2011) has thus expressed insufficient budget to develop TEVT as 'Though this could be a satisfactory aspect, share of TEVT budget in GDP was a mere $0.617 \%$ and $15 \%$ in education budget in 
2011/12. Nevertheless it has been noted that the present allocation to TEVT is not enough if government intends to develop TEVT as a strong subsector in national education and economic scenario'. Furthermore the meager effort and initiation to develop TEVT in Nepal has deescalated more because of the migration trend. More and more youths have found migrated abroad for higher education. According to Saishik Paramarsha Sangh, 47 different countries have been the destinations of the students. The popular destinations for the student are America, United Kingdom and Australia (Awasthi, 2009).

When the labor Act of 1985 was approved by the Nepalese government, there was an official recognition of the potential value of foreign labor migration. In 1999 National Labor Policy gave a provision to provide continuity to foreign employment service profession through institutional development. This policy has also initiated the increase in foreign employment and to make it more reliable, consequently it can be observed that the number of migrants is increasing in most of the fiscal years.

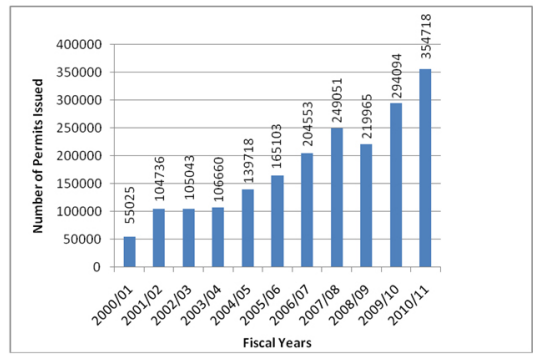

Fig. 1. Number of Works Permits Issued

Source: Based on data obtained from the Department of Foreign Employment.

The number of work permits issued in the fiscal year 2001/02 to $2010 / 11$ shows mostly the increasing trend. In the beginning of the new millennium about 55025 migrants had gone abroad for the employment which was $2.67 \%$ of the total people who had gone abroad during the first decade, 2000/2001 to 2010/11. Since then up to the fiscal year 2002/03 there was a rapid increase in the number 
of migrants that read 104736 and 105043 in the fiscal year 2001/02 and 2002/03 respectively. Then it plunged to 106660 during $2003 / 04$ but it escalated quite consistently up to the fiscal year 2007/08 and reached 249051. Furthermore after a brief drop in the fiscal year 2008/09 the number of migrants increased dramatically and reached 354718 in 2010/11. As a whole there was an increase of above $14.46 \%$ of labor migrant from the fiscal year $2000 / 01$ to 2010/11.

Moreover country's economy has been supported appreciably by the remittance. About $14.2 \%$ of GDP in 2004 was covered by remittance. In 2009 the share of remittance in Gross Domestic Product was $22.9 \%$ and the share of remittance in GDP was $20 \%$ each in the year 2010 and 2011 respectively. It can be understood from the above data that the migratory culture is rapidly being consolidated drawing government attention to review and reform the policies in favor of migration. As far as TEVT is concerned the government and public interest is seemingly being less and less than many other disciplines on one hand and on the other hand the benefit out of TEVT is just a small scrap. Several researches have demonstrated a feeble outcome of TEVT due to various problems. The World Bank (2012) noted that 'The problems are particularly acute in developing countries. Moreover, the bank has clarified that firstly many workers in these countries have very low levels of education and lack of the basic cognitive skills to succeed in the labor market. Secondly training programs in these countries often provide skills that are not in demand. The programs also under provide the analytical and behavior skills the firms demand and that are critical for enabling innovation and creating high productivity jobs'. Employment in abroad is more promising than that in native society. Very little or no skills in intended job gives a chance to the employee to fit in. Whereas natively such trainings are not promising. 'The national TEVT system is perceived to be irrelevant, ineffective, and inefficient with weak links to labor market demands that results in; 1- higher rate of unemployment among graduates of TEVT than among the uneducated; 2- unemployment among Nepalese job seekers, while workers from India in manufacturing sector constitute $15 \%$ of the workforce and 3- orientation of most 
training programs in rural areas to subsistence activities rather than employability' (CTEVT, 2011b).

The migration trend in Nepal has dominated most of the developmental discipline dramatically leaving some of them in jeopardy. Besides TEVT itself has not been able to exist as a strong element to support both the economy as well as the people in the country. Industrial sector is comparatively considered higher productive than agriculture, however a large majority of economically active population (73.4\%) is engaged in subsistence agricultural occupation (CBS, 2008). Industrial sectors' contribution has been declined by $2.8 \%$ since the beginning of new millennium. With the economic growth rate of $4.6 \%$ the growth rate of industrial sector was $1.6 \%$ (MOF, 2012). Among the major problems in executing TEVT programs, funding by foreign countries is one of them hence there is a bit of miss match between programs and actual demand in the society as influence of the donor countries in terms of formulating TEVT programs has somewhat constrained the development of vocational education and training in the country.

'Basic education was implemented from the impression of India, multipurpose schools were run because of American impression and new education system plan was implemented because of the impression of Japanese and other western countries' (Sharma, 2003). Other problem in TEVT development in Nepal is quantitative approach. CTEVT (2011c) addresses, 'Governments' focus lies in expanding the TEVT programs rather than quality control'. Furthermore less emphasis is given to self employment in Nepalese society. The trend of finding jobs in the market after the completion of the vocational training is prevalent in Nepalese societies, which conversely discourage the trainees to establish the business of their own. In fact self employment is not precisely considered as an employment in the society. This type of perspective plays an important role to place the value of vocational education and training in less priority because self employment is socially believed to be of less prestigious than employment gained in any firm. TEVT is potential to provide intended skills to the trainees so that they could either be employed in any firm or be self employed. Therefore a social consideration of a unique perceiving of TEVT 
values, many potential trainees are discouraged to be self employed deescalating the actual output of TEVT programs in Nepalese society. On one hand the qualitative part of TEVT program could not literally allow the trainees to complete in the international market and on the other hand social perspective regarding TEVT in Nepal is not optimistic which eventually restricts the development and utility of vocational education and training to some extend in Nepalese societies.

\section{TEVT Programs in Different Geographical and Political Regions}

Nepal is a land lock country located between two giant countries, India and China. It lies between the $26^{\circ} 22^{\prime}$ to $30^{\circ} 27^{\prime}$ Northern latitude and $80^{\circ} 4^{\prime}$ to $88^{\circ} 12^{\prime}$ Eastern longitude covering $147191 \mathrm{sq}$ $\mathrm{km}$. Ecologically Nepal extends from Terai plains to Mountains through Hill region. According to 2011 national census population distribution in Mountain, Hill and Terai region is $6.73 \%, 43 \%$ and $50.27 \%$ respectively. In the political division Nepal is divided into five development regions namely Eastern Development Region; Central Development Region; Western Development Region; Mid Western Development Region and Far Western Development Region with the population distribution of $21.93 \%, 36.44 \%, 18.6 \%$, $13.4 \%$ and $9.63 \%$ respectively. Similarly population distribution in Urban areas (municipality) is $17 \%$ and in rural areas (Village Development Committee) is $83 \%$. Furthermore the country is divided into 14 zones, 75 district and 58 municipal areas and 3915 VDCs. Again in order to analyze the utility of vocational education and training programs in different geographical and political division it is important to observe the areas and population density in those regions. Eastern Development Region that covers 28456 sq $\mathrm{km}$ of area is $19.3 \%$ of the total area with 204 people living in one square $\mathrm{km}$ of areas. Similarly Central, Western, Mid Western and Far Western Development Regions covering $27410 \mathrm{sq} \mathrm{km}$ (18.6\%), $29398 \mathrm{sq} \mathrm{km} \mathrm{(20 \% ),} 42378 \mathrm{sq} \mathrm{km} \mathrm{(28.8 \% )} \mathrm{and} 19539 \mathrm{sq}$ $\mathrm{km}(13.3 \%)$ of area have 352, 168, 84 and 131 people living in a square $\mathrm{km}$ of area. 
It has been found quite often that the TEVT programs have launched in an urban area or near by the urban areas rather than in remote areas in Nepal like in most of the developing countries. Several researches have pointed out this scenario to be one of the major issues related with vocational education and training programs.

There are very few TEVT opportunities available in rural areas. If ever there would be a TEVT institution most likely it would be situated in a nearby rural town (King, 2007). This claim holds quite good in the case of Nepal as most of the programs are in Terai Region and if they are in Hill and Mountain in region they are situated near by the developed towns. Geographical difficulties and harsh climatic condition could be the excuses for this fact. Presently there are 25 constituted schools/ training centers of CTEVT, 305 diploma level private institutions, 480 TSLC (Technical School Leaving Certificate) level and 55 short term vocational training providing institutions affiliated to CTEVT and 45 Community schools offering TSLC level named as annex programs (CTEVT, 2011d). TSLC level runs about 19 programs that focus on vocational training and most of the programs are run in Terai region. Out of these programs medical programs like CMA (Community Medical Assistant) and ANM (Auxiliary Nurse Midwifery) are the most popular in Nepal. Topographically these two programs are conducted mostly in Terai region. In Mountain region the number of ANM and CMA programs are 1 and 2 respectively whereas in Hill area ANM is 18 and CMA is 29 in number similarly in Terai area number of ANM program is 24 and that of CMA is 41. Analyzing the number of ANM and CMA programs in developmental region wise it is again seen that the programs are concentrated in the eastern, central and western developmental region. ANM program in these regions are 15, 12, and 11 respectively and the program in Mid Western and Far Western region is only 2 and 3 respectively. In the case of CMA program, the number is 22, 23, 16,8 and 3 in Eastern, Central, Western, Mid Western and Far Western Development region respectively.

In diploma program out of 305 programs Mountain region has 2, Hill has 134 and Terai region has 169 programs. Moreover to observe the diploma programs on the basis of developmental region 
Eastern Development region has 51, Central has 171, Western, Mid Western and Far Western Development region has 45, 25 and 13 programs respectively. In comparison, Terai and Hill region are more developed than Himalayan region in terms of physical infrastructure and resources hence most of the TEVT programs are found to be concentrated in Terai and Hill region. Similarly Central development region is the most developed region because the capital of Nepal is located in this region furthermore Eastern and Western Development region are situated on the either side of the Central Development region hence these two regions are also developed as compared to Mid Western and Far Western Development region. Therefore TEVT programs are mostly located in the Central then in Eastern followed by Western Development region. Mid Western and Far Western regions are least developed regions thus the number of TEVT programs are less. Besides private investment in TEVT sector has the similar trend. 'It shows that private investment in TEVT sector mostly falls on well facilitated or resourceful area like capital city and Terai region giving less focus on Hill and Mountain region (CTEVT, 2011e). To observe the geographical and political division on the basis of literacy rate the situation is similar as mentioned above. TEVT programs have further introduced several provisions of incentives to the backward and low caste groups but the beneficiaries of these incentive programs are from the developed geographical and political regions leaving the intensely needy groups beyond the reach of the TEVT programs in Nepal. Failure to reach the needy people in the remote places is one of the serious issues of TEVT strategy which has constricted the overall development of TEVT programs in the country.

\section{Conclusion}

Efforts to set any community free from the poverty would be the most significant objective of any state and vocational education and training strategy has been adapted by many countries to head towards the sophisticated world. This study has analyzed the way the vocational education and training programs cracked in the Nepalese society for the socioeconomic development. In fact the development of TEVT was initiated with an influence of basic education in India 
in 1947 which further was elaborated as multipurpose education system in 1958. Then compulsory vocational education under NESP was adapted in 1971 until CTEVT was established as an apex body for the development of TEVT in Nepal. Development of TEVT in Nepal was not impressive through out due to various problems. Many socio-cultural factors had played an important role in constraining TEVT development.

Caste and class system that were prevalent in Nepal from the very beginning had treated many Nepalese unjustifiably in many social function including their access in TEVT. Caste defined behavior had left not many options for many Nepalese in selecting their profession of their interest and potential. Therefore the policies, not sharply against people's mentality would be favorable in TEVT development in Nepalese society.

Traditional behavior pattern was another factor that indirectly restricted many Nepalese to be benefited from many opportunities. Kinship, marriage system and gender issues had framed many people to be customary. Consequently they simply became a victim of modern and competitive globalised world. The main concern of traditional pattern was the social status along with property and heritage conservation because of which people could not claim the benefits of TEVT programs. Patrilineal and partilocal system in Hindu religion had focused more on their custom rather than any other programs like TEVT depriving many from the TEVT programs especially in rural part of the country. Moreover migratory culture had flourished substantially, on one hand which had helped many people to find a path to move away from their hardship. Whereas on the other hand TEVT in comparison to the employment opportunity in abroad had found to be quite less beneficial in terms of financial gain. Besides the quality in TEVT program was not up to the international standard and this had caused people to underestimate the value of such programs. Lastly the places where the TEVT programs were launched were mostly in the developed cities or nearby them. More precisely the remote areas where the under privileged people who were genuinely in need of skills and knowledge for their living were facing difficulties to reach such programs which had hurdled TEVT program to develop promisingly. 


\section{References}

Asian Development Bank. (2006). Project administration memorandum for the loan to the government of Nepal for the skills from employment project. Retrieved from http://www2.adb.org/Documents/ PAMs/Nep/36611-NEP-PAM.pdf.

Almeida, R., Behrman, J., \& Robalino, D. (2012). The right skills for the job? Rethinking training policies for workers. Washington D.C: The World Bank

Awasthi. Gokarna, (2009 October 27). 'Baidesik Shiksha ko Lahar'. The Kantipur National Daily, pp.1.

Belbase, L.N. (1981). Problems of planning and implementing vocational education in developing countries: A case of Nepal. Unpublished doctoral dissertation, Southern Illinois University, Carbondale, USA.

Bhandari, U. (2013). Technical Vocational Education and Training (TVET) Development and social inclusion in Nepal. Technical and Vocational Education and Training Development Journal, 1(13), 30-36. Retrieved from http://www.ctevt.org.np/files/ ResearchJournal2013.pdf

Bista, D. B., (1961). Sabai jaat ko phulbari. In Bishnu P Dahal (Ed.), An Analysis of Nepali Culture and Society. (pp. 69-79). Lalitpur: Adhikari Books \& Stationary.

Bista, D.B., (1982). The process of Nepalization. In Bishnu P Dahal (Ed.), An Analysis of Nepali Culture and Society. (pp. 58-68). Lalitpur: Adhikari Books \& Stationary. Bista, D.B., (1989). The structure of Nepali society. In Bishnu P Dahal (Ed.), An Analysis of Nepali Culture and Society. (pp. 32-47). Lalitpur: Adhikari Books \& Stationary.

Central Bureau of Statistics, (2008). Nepal labor force survey 2010. Kathmandu, Nepal: Central Bureau of Statistics

CBS. (2011). National Report of Population and Housing Census, 2011/12. Kathmandu: Central Bureau of Statistics. CTEVT, (2011). A study of technical education and vocational training programs in Nepal. General Federation of 
Nepalese Trade Unions (GEFONT), Kathmandu, Nepal.

Department of Education. (2012). Flash I Report 2012-2013.

Sanothimi, Bhaktapur: Department of Education.

Department of Education. (2012). Status Report 2012. Sanothimi, Bhaktapur: Department of Education.

King, K. (2007). The role of UNESCO in supporting and promoting TEVET in the Asian-Pacific region. Paris: UNESCO.

Ministry of Education. (2009). Technical education and vocation training. Compendium on Education Policy in Nepal. Kathmandu: Ministry of Education.

Ministry of Finance. (2012). Economic survey 2011/12. Kathmandu: Ministry of Finance.

Prospects, N 135. (2005). Orientating TVET for sustainable development. Geneva: UNEVOC and IBE.

Sharma, T.N. (2005). Connecting technical education and vocational training with employment in Nepal: Current problems, issues and trends. Technical and Vocational Education and Training Development Journal, 1(9), 1-13.

UIS (2006). Participation in Formal Technical and Vocational Education and Training Programs Worldwide: An Initial Statistical Study. Bonn: UNESCOUNEVOC.

Vollmann, W. (2010). The challenge of technical and vocational training and education in rural areas: The case study of South Asia. Journal of Education and Research. 2, 52-58. Retrieved from http://www.nepjol.info/ index.php/JER/article/view/7623/6200.

World Bank. (2011). Nepal: Enhanced vocational education and training project (EVENT). Kathmandu: World Bank. 